\title{
Low use of statins and other coronary secondary prevention therapies in primary and secondary care in India
}

This article was published in the following Dove Press journal:

Vascular Health and Risk Management

19 November 2009

Number of times this article has been viewed

\author{
Krishna K Sharma' \\ Rajeev Gupta ${ }^{2}$ \\ Aachu Agrawal ${ }^{3}$ \\ Sanjeeb Roy ${ }^{2}$ \\ Atul Kasliwal ${ }^{2}$ \\ Ajeet Bana ${ }^{2}$ \\ Ravindra K Tongia ${ }^{2}$ \\ Prakash C Deedwania ${ }^{4}$ \\ 'Department of Pharmacy, LBS \\ College of Pharmacy, Jaipur, India; \\ ${ }^{2}$ Departments of Medicine, Cardiology \\ and Cardiac Surgery, Fortis Escorts \\ Hospital, Jaipur, India; ${ }^{3}$ Department \\ of Home Science, University of \\ Rajasthan, Jaipur, India; ${ }^{4}$ Department \\ of Cardiology, University of California \\ San Francisco-VA Health System, \\ Fresno, CA, USA
}

Objective: To determine the frequency of use of pharmacotherapy with aspirin, beta blocker, statin, and angiotensin-converting enzyme (ACE) inhibitor in patients with stable coronary heart disease (CHD) among physicians at different levels of health care in Rajasthan state, India.

Methods: Physicians practicing at tertiary hospitals and clinics at tertiary, secondary and primary levels were contacted. Prescriptions of CHD patients were audited and descriptive statistics reported.

Results: We evaluated 2,993 prescriptions (tertiary hospital discharge 711, tertiary 688, secondary 1,306, and primary 288). Use of aspirin was in 2,713 (91\%) of prescriptions, beta blockers 2,057 (69\%), ACE inhibitors or angiotensin receptor blockers (ARBs) 2,471 (82\%), and statins 2,059 (69\%). Any one of these drugs was prescribed in 2,991 (100\%), any two in 2,880 (96\%), any three in 1,740 (58\%), and all four in 1,062 (35.5\%) $(P<0.001)$. As compared to tertiary hospital, prescriptions at tertiary, secondary, and primary levels were lower: aspirin ( $96 \%$ vs $95 \%, 91 \%, 67 \%$ ), beta blockers ( $80 \%$ vs $62 \%, 66 \%, 70 \%$ ), statins ( $87 \%$ vs $82 \%, 62 \%$, $21 \%$ ): two drugs ( $98 \%$ vs $96 \%, 98 \%, 85 \%$ ), three drugs ( $75 \%$ vs $58 \%, 55 \%, 28 \%$ ), or four drugs $(54 \%$ vs $44 \%, 28 \%, 7 \%)(P<0.01)$. Use of ACE inhibitors/ARBs was similar while nitrates ( $43 \%$ vs $23 \%, 43 \%, 70 \%$ ), dihydropyridine calcium channel blockers ( $12 \%$ vs $15 \%, 30 \%, 47 \%$ ), and multivitamins ( $6 \%$ vs $26 \%, 37 \%, 47 \%)$ use was more in secondary and primary care.

Conclusions: There is suboptimal use of various evidence-based drugs (aspirin, beta blockers, ACE inhibitors, and statins) for secondary prevention of CHD in India.

Keywords: statins, coronary heart disease, aspirin, beta blockers, angiotensin-converting enzyme inhibitor

\section{Background}

Guidelines based on evidence from randomized controlled trails recommend that aspirin, beta-adrenergic blockers, angiotensin-converting enzyme (ACE) inhibitors, and hydroxyl methyl glutarate coenzyme A reductase inhibitors (statins) be used in all patients with symptomatic chronic stable angina or asymptomatic survivors of acute myocardial infarction and following percutaneous coronary intervention or coronary bypass surgery for secondary prevention of myocardial infarction, stroke and death. ${ }^{1-4}$ It has been hypothesized that if used collectively these agents could reduce long term risk of cardiovascular events and mortality by as much as $75 \% .^{5}$ However the actual impact depends on the extent to which they are used in practice..$^{6-8}$

The EUROASPIRE studies of pharmacological practice patterns in stable coronary heart disease (CHD) patients evaluated secondary prevention in nine countries in Europe. ${ }^{9-11}$ In the first study a very low use of ACE inhibitors and lipid-lowering
Correspondence: Rajeev Gupta Department of Medicine, Fortis-Escorts Hospital, JLN Marg, Jaipur 3020I7, India Tel +9I I4I 2547000

Fax +9| |4| 400 8I5|

Email rajeevgg@gmail.com 
drugs and suboptimal use of aspirin and beta-blockers was observed. ${ }^{9}$ The EUROASPIRE-2 study reported increasing, though suboptimal, use of antiplatelet agents, ACE inhibitors and beta-blockers and a large increase in statin use. ${ }^{10}$ The EUROASPIRE-3 study has reported unchanged use for prescriptions for beta-blockers, ACE inhibitors or angiotensin receptor blockers (ARBs) and statins. ${ }^{11}$ The North American National Registry of Myocardial Infarction (NRMI) reported a low use of such therapies in 1990s (NRMI-1) with a subsequent increase in follow-up studies (NRMI-2 and NRMI-3). ${ }^{12}$ On the other hand, the World Health Organization (WHO) PREMISE study in eight low and middle income countries in Asia, Africa, Europe, and South America reported low and variable use in patients with established cardiovascular diseases including survivors of coronary event or stroke. ${ }^{13}$ Use of all types of evidence-based medical therapies (aspirin, beta-blockers, ACE inhibitors, statins) was low in this and other studies in India. ${ }^{13-16}$ On the other hand, a large acute coronary syndrome registry reported high use of evidence-based therapies in secondary and tertiary care hospitals. ${ }^{17}$ Attrition of such therapies as these patients shift to chronic care is not known.

Presently, there is no significant information on the prescribing pattern of recommended drugs for secondary prevention of CHD at various levels of health care (primary, secondary, tertiary, or tertiary hospital-based) in India. Frequency of use of multiple nonevidence-based therapies in stable patients with CHD has also not been well documented. We analyzed use of evidence-based medicines for secondary prevention of CHD among patients with symptomatic chronic stable angina or survivors of acute coronary syndromes in settings of rural and urban primary, secondary, tertiary care, and tertiary care hospital discharge levels.

\section{Methods}

The study was approved by the local institutional ethics committee. A proforma was prepared that included demographic details of patients, diagnoses, and drug prescriptions. Data on demographic and personal detail of physicians were also collected. Physicians were classified as primary care physicians who had basic qualifications and were working in rural or urban clinics and dispensaries; secondary level physicians were having a postgraduate qualification in internal medicine and practising independently or in government clinics, primary health centers or secondary level government or private hospitals; and tertiary level physicians were those with subspecialty qualification in cardiology, cardiac surgery, endocrinology, etc, and tertiary level hospitals with cardiac invasive and surgical management. The trade names of drugs were deciphered and classified into pharmacological groups that included aspirin, clopidogrel or other antiplatelet agents, beta-blockers, ACE inhibitors or ARBs, statins, other lipid-lowering medicines such as fenofibrate, short- and long-acting nitrates, dihydropyridine or nondihydropyridine calcium channel blockers (CCBs), potassium channel openers (eg, nicorandil), metabolic modulators (eg, trimetazidine), antioxidants, multivitamins, diabetic medications, and other medications.

The study was performed at all large districts of Rajasthan state over a period of 15 months from September 2007 to December 2008. Rajasthan is the largest state in India and is at the median of the national human development index and other social indices. Consent from the physicians prescribing at primary, secondary, and tertiary sites was obtained and the prescriptions were studied during a single day at the local pharmacy. This was to minimize bias and negate the influence of changing the prescribing habit once awareness of monitoring was apparent. We could evaluate prescriptions of 43 general practitioners or primary care physicians, 61 internists or secondary care physicians, eight diabetologists, and 18 cardiologists in tertiary care and tertiary care hospital discharge prescriptions from three tertiary care hospitals with 14 cardiologists. The age-distribution of these physicians is shown in Table 1. The primary and secondary care physicians are older than those working at tertiary care centers and hospitals. The state has more than 20,000 registered qualified medical practitioners at primary, secondary, and tertiary care levels. Details of specialization are not available at the local medical council.

Table I Age of physicians at different health care levels

\begin{tabular}{lllll}
\hline Age-groups & $\begin{array}{l}\text { Tertiary care } \\
\text { hospital }(\mathbf{n}=\mathbf{1 4})\end{array}$ & $\begin{array}{l}\text { Tertiary care } \\
\text { physicians }(\mathbf{n}=\mathbf{2 6})\end{array}$ & $\begin{array}{l}\text { Secondary care } \\
\text { physicians }(\mathbf{n}=\mathbf{6 1})\end{array}$ & $\begin{array}{l}\text { Primary care } \\
\text { physicians }(\mathbf{n}=\mathbf{4 3})\end{array}$ \\
\hline $30-45$ & $6(42.9)$ & $11(42.4)$ & $21(34.5)$ & $13(30.2)$ \\
$46-60$ & $6(42.9)$ & $13(50.0)$ & $25(40.9)$ & $17(39.5)$ \\
$60+$ & $2(14.2)$ & $2(7.5)$ & $15(24.5)$ & $13(30.2)$ \\
\hline
\end{tabular}

Note: Numbers in parentheses are percentages. 
Interviews were organized with the patients after their consent and only those patients who had an established diagnosis of CHD are included. Approximately $60 \%$ of eligible patients $(3,013 / 5,000)$ recruited from the outpatient clinics of primary, secondary, and tertiary health care facilities and tertiary care hospitals agreed to provide details of prescriptions. Twenty prescriptions were illegible and 2,993 were included in the prescription audit. The medicines obtained from these prescriptions were deciphered and trade names translated into pharmacological molecules.

\section{Statistical analyses}

All the data were analyzed centrally using SPSS software (v. 10.0; SPSS Inc., Chicago, IL). Descriptive data are reported as numbers and percentages. The significance of intergroup differences was analyzed using chi-squared test. Trends in prescribing patterns at different levels of care were assessed using Mantel-Haenszel chi-squared test for trend. Odds ratio (OR) was used to assess difference in use of various drugs at tertiary, secondary, and primary level of care compared with tertiary level hospital discharge $(\mathrm{OR}, 1.0)$ and were calculated using logistic regression analyses. $P$ values $<0.05$ were considered significant.

\section{Results}

We evaluated 2,993 persons and their prescriptions (tertiary level hospital discharge, 711; tertiary level specialists, 688; secondary care physicians, 1,306 ; primary care physicians, 288). In a recent national study of health care-seeking behavior for chronic diseases, it was reported that $21.5 \%$ patients visited primary level care, $52.4 \%$ utilized secondary level care, and $26.1 \%$ accessed tertiary level care. ${ }^{18}$ This is similar to the present study enrollment and shows that more than $50 \%$ of patients with chronic diseases access secondary level care for their treatment (Table 2). The mean age of patients in the study was $60.5 \pm 14.1$ years, more than $50 \%$ of patients were aged $45-65$ years, and $70.6 \%$ were men. The median time after the acute coronary event or diagnosis of stable CHD was 30 months (interquartile range, 18-54 months).
The largest group of patients was with stable angina pectoris $(65 \%)$ followed by survivors of unstable angina or acute myocardial infarction.

Use of various drugs classes is shown in Table 3. Aspirin was prescribed in 2,713 (90.6\%), beta blockers in 2,057 (68.7\%), ACE inhibitors or ARBs in 2,471 (82.5\%), statins in 2,059 (68.8\%), other lipid-modifying drugs in 405 (13.5\%), nitrates in 1,228 (41.1\%), dihydropyridine CCBs in 716 (23.9\%), nondihydropyridine CCBs in 423 (14.1\%), potassium channel openers in $481(16.1 \%)$, myocardial metabolic modulators in 424 (14.2\%), antioxidants in 257 (8.6\%), vitamins in 839 (28.0\%), and diabetes medications in 1,163 (39.3\%). Any one of the four evidence-based drugs (aspirin, beta-blockers, ACE inhibitors/ARBs, and statins) was prescribed in 2,991 (99.9\%) subjects, any two in $2880(96.2 \%)$, any three in $1,740(58.1 \%)$, and all four in $1062(35.5 \%)$ ( $\chi^{2}$ for trend, $\left.P<0.001\right)$. As compared to tertiary care hospital discharge, the respective prescriptions at tertiary care, secondary care, and primary level care were significantly lower for aspirin $(96.1 \%$ vs $94.6 \%$, $90.8 \%, 67.0 \%$, respectively), beta blockers $(79.6 \%$ vs $62.1 \%, 66.1 \%, 69.8 \%$, respectively), statins ( $86.9 \%$ vs $82.4 \%, 62.3 \%, 20.8 \%$, respectively) as well as for two drug (97.7\% vs $96.3 \%, 97.5 \%, 85.1 \%$, respectively), three drug ( $75.4 \%$ vs $58.4 \%, 55.3 \%, 27.8 \%$, respectively), or four drug $(53.7 \%$ vs $43.5 \%, 27.7 \%, 6.6 \%$, respectively) combinations ( $\chi^{2}$ for trend, $P<0.01$ ) (Figure 1). Use of nitrates (43.4\% vs $23.1 \%, 43.0 \%, 69.8 \%$, respectively), dihydropyridine calcium channel blockers ( $12.3 \%$ vs $15.4 \%, 29.6 \%$, $47.2 \%$, respectively), antioxidants ( $0.8 \%$ vs $12.6 \%, 11.3 \%$, $5.9 \%$, respectively) and multivitamins (6.3\% vs $25.6 \%$, $37.1 \%, 46.5 \%$, respectively) was greater in primary and secondary care. Use of ACE inhibitors/ARBs was more common in patients at tertiary and secondary care levels (Table 3).

Univariate statistics revealed that as compared to tertiary care hospital discharge prescriptions there was a gradual attrition of prescriptions of aspirin, beta blockers, ACE inhibitors/ ARBs and statins in chronic tertiary care, secondary care,

Table 2 Utilization of health care as outpatient services for chronic diseases in India and the present study

\begin{tabular}{lll}
\hline & $\begin{array}{l}\text { Chronic care foundation } \\
\text { of India national study }{ }^{18} \\
(\mathbf{n}=\mathbf{I , 8 5 6 )}\end{array}$ & $\begin{array}{l}\text { Present study subjects } \\
\text { excluding tertiary hospital } \\
\text { discharge }(\mathbf{n}=\mathbf{2 , 2 8 2})\end{array}$ \\
\hline Primary care & $21.5 \%$ & $12.6 \%$ \\
Secondary care & $52.4 \%$ & $57.2 \%$ \\
Tertiary care & $26.1 \%$ & $30.1 \%$ \\
\hline
\end{tabular}


Table 3 Frequency of use of various drug classes at different prescriber levels

\begin{tabular}{|c|c|c|c|c|c|c|}
\hline Drug group & $\begin{array}{l}\text { Total } \\
(n=2,993)\end{array}$ & $\begin{array}{l}\text { Tertiary care } \\
\text { hospital } \\
(n=7 \mid I)\end{array}$ & $\begin{array}{l}\text { Tertiary care } \\
\text { level physicians } \\
(n=688)\end{array}$ & $\begin{array}{l}\text { Secondary care } \\
\text { level physicians } \\
(n=I, 306)\end{array}$ & $\begin{array}{l}\text { Primary } \\
\text { care level } \\
(n=288)\end{array}$ & $\begin{array}{l}\chi^{2} \text { square for } \\
\text { trend }(P \text { value })\end{array}$ \\
\hline Aspirin & $2,7 \mid 3(90.6)$ & $683(96.1)$ & $65 I(94.6)$ & $\mathrm{I}, \mathrm{I} 86(90.8)$ & $193(67.0)$ & $101.41(<0.001)$ \\
\hline Beta blockers & $2,057(68.7)$ & $566(79.6)$ & $427(62.0)$ & $863(66.1)$ & $201(69.8)$ & $8.08(0.004)$ \\
\hline ACE inhibitors/ARBs & $2,47 \mid(82.5)$ & $544(76.5)$ & 607 (88.2) & I, I I $2(85.1)$ & $208(72.2)$ & $0.005(0.946)$ \\
\hline Statins & $2,059(68.8)$ & $618(86.9)$ & $567(82.4)$ & $814(62.3)$ & $60(20.8)$ & $170.77(<0.001)$ \\
\hline Other anticholestrol drugs & $405(13.5)$ & $142(20.0)$ & $102(14.8)$ & $150(\mid 1.5)$ & II (3.8) & $28.35(<0.001)$ \\
\hline Nitrates & $\mathrm{I}, 228(4 \mathrm{I} . \mathrm{I})$ & $308(43.4)$ & $158(23.1)$ & $56 I(43.0)$ & $201(69.8)$ & $31.91(<0.001)$ \\
\hline Dihydropyridine CCB & $716(23.9)$ & $87(12.3)$ & $106(15.4)$ & $387(29.6)$ & $136(47.2)$ & $172.29(<0.001)$ \\
\hline Nondihydropyridine CCB & $423(14.1)$ & $30(4.2)$ & $110(16.0)$ & $250(19.1)$ & $33(11.5)$ & $23.25(<0.00 \mathrm{I})$ \\
\hline Potassium channel openers & $481(16.1)$ & $16(2.3)$ & $139(20.0)$ & $291(22.3)$ & $35(12.2)$ & $15.86(<0.001)$ \\
\hline Metabolic modulators & $424(14.2)$ & $13(1.8)$ & I 77 (25.7) & $222(17.0)$ & $12(4.2)$ & $5.42(0.02)$ \\
\hline Antioxidants & $257(8.6)$ & $6(0.8)$ & $87(12.6)$ & I47 (II.3) & $17(5.9)$ & $12.45(<0.001)$ \\
\hline B-complex or multivitamins & $839(28.0)$ & $45(6.3)$ & $176(25.6)$ & $484(37.1)$ & $134(46.5)$ & $262.24(<0.001)$ \\
\hline Other medications & $\mathrm{I}, 86 \mathrm{I}(62.2)$ & $443(62.1)$ & $44 I(64.1)$ & $811(62.1)$ & $166(57.6)$ & $1.32(0.25 \mathrm{I})$ \\
\hline Diabetes medications & I, $163(39.1)$ & $133(19.0)$ & $324(47.2)$ & $602(46.2)$ & $104(36.2)$ & $10.74(0.001)$ \\
\hline
\end{tabular}

Abbreviations: $A C E$, angiotensin-converting enzyme; $A R B$, angiotensin receptor blockers; $C C B$, calcium channel blockers.

and primary care, respectively $\left(\chi^{2}\right.$ for trend, $\left.P<0.001\right)$ (Table 3). Use of combinations of evidence-based therapies (aspirin, beta-blockers, ACE inhibitors/ARBs, and statins) was also significantly lower at primary and secondary level of care. As compared with tertiary level hospitals, the OR (95\% confidence intervals [CI]) for use of two, three, and four drug combinations at primary care was OR, $0.13(95 \%$ CI: 0.07-0.24), OR, 0.13 (95\% CI: 0.09-0.17) and OR, 0.06 (95\% CI: $0.04-0.01)$ and at secondary care was OR, 1.01 (95\% CI: $0.55-1.88)$, OR, 0.40 (95\% CI: $0.33-0.49$ ), and OR, 0.33 (95\% CI: 0.27-0.40), respectively (Table 4).

\section{Discussion}

This study shows that in the Rajasthan state of India, the use of evidence-based secondary prevention cardiovascular therapies is low in chronic management of CHD at primary and secondary care levels. The use appears adequate at tertiary level hospital discharge. But here also is lower than recommended by the American College of Cardiology/American Heart Association guidelines ${ }^{1}$ and British quality outcomes framework. ${ }^{19}$ High use of nonevidence-based dihydropyridine CCBs, nitrates, antioxidants, and multivitamins in primary and secondary care is also observed.

There is robust scientific evidence for recommending the use of aspirin, lipid-lowering agents especially statins, betaadrenergic blockers, and ACE inhibitors for the secondary prevention of cardiovascular disease. ${ }^{1-4}$ Multiple large studies as well as meta-analyses have reported decreased clinical events and mortality and there is incremental benefit with their use. ${ }^{5}$ Historically mortality in chronic cardiovascular diseases range from $8 \%-15 \%$ per annum. ${ }^{20}$ This mortality can be decreased by currently available evidence-based therapies and it has been determined that incremental use of aspirin, beta blockers, statins, and ACE inhibitors can reduce the two-year cardiovascular mortality from $8 \%$ to $2.3 \% .{ }^{5}$ Multiple national and international guidelines recommend that for secondary prevention aspirin, beta-blockers and statins be used in all the patients and ACE inhibitors should be used in those with left ventricular dysfunction. ${ }^{21}$ However, after publication of Heart Outcomes Prevention Evaluation (HOPE) study ${ }^{21}$ there is a strong evidence of adding ACE inhibitors to other drugs and ACCF/AHA guidelines have been since modified. ${ }^{1}$ Use of ARBs instead of ACE inhibitors as primary drugs is controversial and is not recommended. ${ }^{23}$

In the present study use of all the four drug classes (aspirin, beta blockers, ACE inhibitors/ARB and statins was high at discharge from tertiary care hospitals included in the study. These findings are similar to studies from North America (NRMI), ${ }^{24}$ western Europe (GRACE), ${ }^{25}$ and the Indian CREATE registry. ${ }^{17}$ In chronic care, on the other hand, the use of various evidence-based therapies rapidly decline with time. ${ }^{7,8}$ Aspirin use in the present study in combined groups at tertiary, secondary, and primary care level is in 2030 of 2,282 patients (88.9\%) which is 

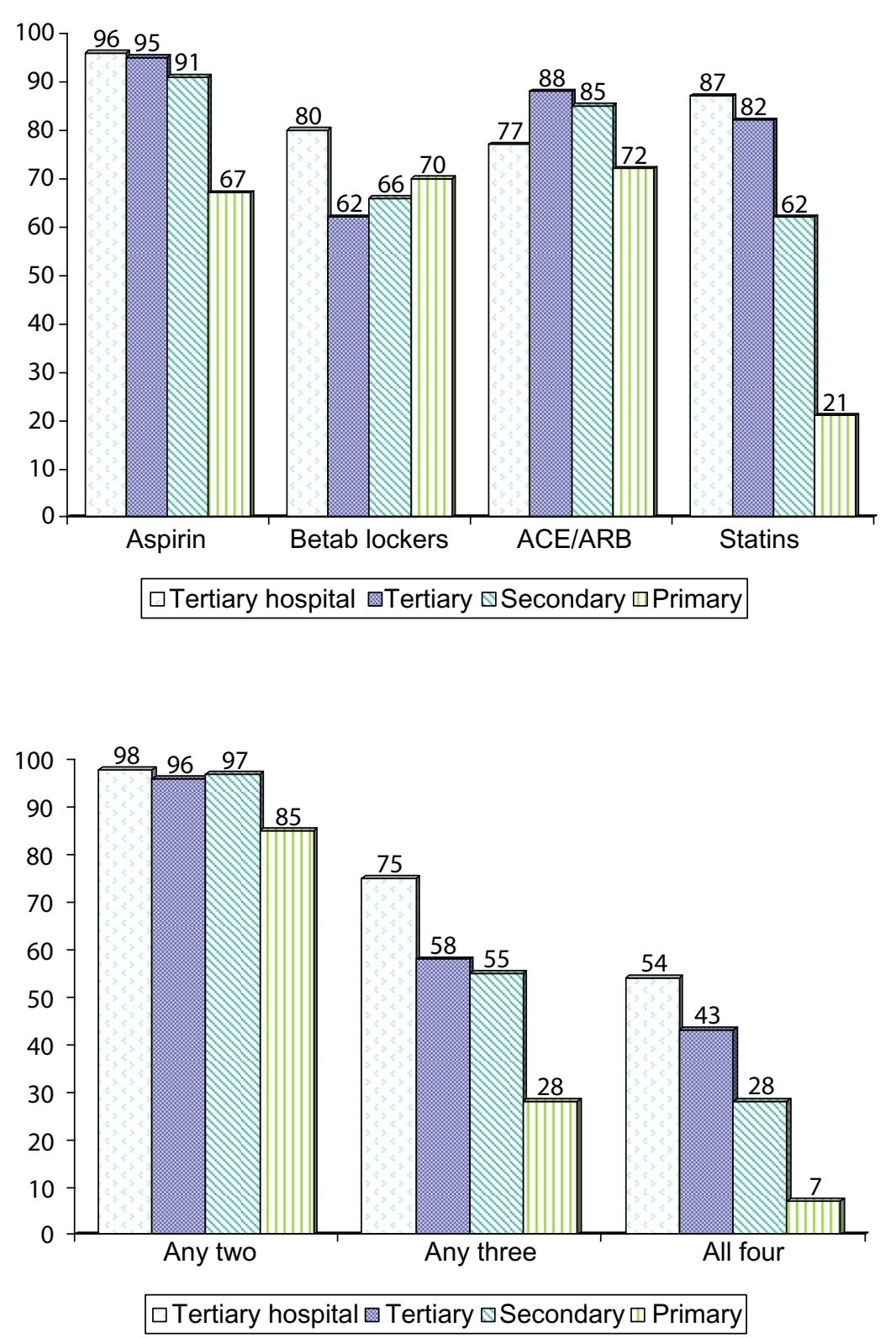

Figure I Percent use of evidence-based therapies at different levels of care. A) Use of aspirin is low in primary care, beta-blocker use is low in tertiary and secondary care clinics, angiotensin-converting enzyme inhibitors/angiotensin receptor blockers (ACE/ARB) use is low in tertiary care and primary care while statin use is low is secondary and primary care. B) Use of multiple therapies shows a significantly declining trends from tertiary care hospital discharge to primary care level $(P$ for trend $<0.0 \mathrm{I})$.

similar to the EUROPASPIRE studies ${ }^{9,10}$ and Indian arm of WHO-PREMISE. ${ }^{13}$ Beta blockers were used in 1,491 (65.3\%), ACE inhibitors/ARBs in 1,927 (84.4\%), and statins in 1,441 (63.1\%). This is significantly greater than the WHO-PREMISE study. The use of beta-blockers and statins is similar to the EUROASPIRE study, but that of ACE inhibitors is greater. The high use of ACE inhibitors/ARBs was observed in all physician groups. Physician prescribing behavior is influenced by multiple factors ${ }^{26}$ and it is likely that aggressive marketing of ARBs have influenced the practice patterns while use of other drugs that are older and were not marketed aggressively is lower.

One of the major limitations of the study is that it has been performed in a single state of India and the results cannot be transposed to the whole country given the considerable social, cultural, and medical service-related heterogeneity of India. On the other hand, in terms of social and economic developmental indices, Rajasthan is at the median level ${ }^{27}$ and the results obtained from various classes of physicians could be similar to the entire nation. Secondly, the study 
Table 4 Odds ratios (95\% confidence intervals) for use of evidence-based therapies at different levels of healthcare compared with tertiary hospital discharge (odds ratio $=1.0$ )

\begin{tabular}{llll}
\hline & Tertiary care & Secondary care & Primary care \\
\hline Any two drugs & $0.61(0.32-1.15)$ & $1.01(0.55-1.88)$ & $0.13(0.07-0.24)$ \\
Any three drugs & $0.46(0.37-0.58)$ & $0.40(0.33-0.49)$ & $0.13(0.09-0.17)$ \\
All four drugs & $0.66(0.54-0.82)$ & $0.33(0.27-0.40)$ & $0.06(0.04-0.10)$ \\
\hline
\end{tabular}

Notes: Therapy with angiotensin-converting enzyme inhibitors or angiotensin receptor blockers; aspirin or other antiplatelets; beta-blockers; or statins.

was confined to major cities and district headquarters of the state and therefore the situation regarding CHD secondary prevention therapies in general population and among patients who attend primary care facilities in rural and semiurban locations was not available. The situation in these locations is likely to be worse than in our sample as has been reported for other disease conditions..$^{27}$ Thirdly, we obtained more prescriptions from physicians at secondary (internists) and tertiary (cardiologists, specialists) levels as compared to those at primary level and this may have skewed the overall prescription pattern. However, it has been reported in India that most of the patients with established CHD either obtain treatment directly from the specialists or the internists, and primary level physicians are not in the cardiovascular care loop. ${ }^{18}$ Fourthly, this is a retrospective prescription audit study rather than a prospective study. But only studies of this kind provide the real-life data and this is a study strength. Similar strategies are used in the EUROASPIRE studies $^{9-11}$ and the EuroHeart surveys. ${ }^{28}$ Fifthly, we have no data of the CHD subtype (acute ST elevation infarction, acute non-Q infarction, unstable angina, chronic stable angina or congestive heart failure), and associated cardiovascular risk factors such as smoking, hypertension, hypercholesterolemia and diabetes. All these can modify prescribing patterns. Sixthly, for statistical analyses we did not control for type of disease, disease severity, cardiovascular risk factors, other comorbidities, physician age, or time in practice. All these can influence prescription and prescribing habits. In the present study, it is observed that physicians at primary and secondary care levels are older than at tertiary care level (Table 1). Older physicians are known to be less compliant with recent developments. ${ }^{67}$ The study shows that this could be a factor that influences prescriptions. And finally, drug treatment is not the only effective method of secondary prevention. ${ }^{1}$ We did not inquire regarding dietary advice, smoking cessation, weight reduction, physical exercise, and other nonpharmacological preventive interventions. The study strengths include a large number of prescriptions analyzed that are more than any contemporary studies from developing countries, a large and heterogeneous geographical distribution of the study locales, short time awareness of the prescribing physicians to the study with unlikely change in prescribing habits, and a single person deciphering the prescriptions. Despite multiple limitations, the study provides a useful insight into current practice with regard to secondary prevention.

The study results show appropriate use of evidence-based therapies at tertiary care level and low use in primary and secondary care shows a slow transmission of knowledge of current evidence-based strategies in secondary prevention of CHD to these physicians. The structure and performance of health systems in this country might be party responsible for this difference..$^{29}$ Other reasons for the treatment gaps observed in this study could be at the level of health systems, health care providers, and patients (Table 5). We have not studied these determinants. Bearing in mind that in this study about three quarters of patients accessed primary and secondary health care facilities for obtaining treatment, these physicians need to be targeted in continuing medical education programs related to secondary prevention and should be provided with suitable incentives to engage in prevention.

In conclusion, despite availability of low-cost and effective pharmacological interventions, ${ }^{30}$ there are significant gaps in secondary prevention of CHD in primary and secondary care in India. There is a need to increase access to preventative drug therapy and to improve the quality of health provider-related care. Health system capacity needs to be enhanced through development of effective national drug policies, rational and evidence-based selection of medicines for inclusion in national drug lists, affordable price for pharmaceuticals, and sustainable financing and supply systems. ${ }^{6}$ Policies are also required to strengthen infrastructure of health care facilities, particularly at the primary and secondary health care levels, and to provide continuing medical education to health care providers. To ensure sustainability of these measures, they need to be supported with complementary population-wide strategies that promote healthy lifestyles and educate individuals regarding the importance of secondary prevention. ${ }^{31}$ Finally, effective 
Table 5 Barriers to adherence to evidence-based therapies for chronic diseases

\begin{tabular}{|c|c|c|}
\hline Health systems related & Health care provider level & Individual patient level \\
\hline $\begin{array}{l}\text { - Low perceived need by health care } \\
\text { bureaucrats and managers }\end{array}$ & $\begin{array}{l}\text { - Lack of proper education and } \\
\text { motivation } \\
\text { - Absent continuing medical } \\
\text { education programs }\end{array}$ & $\begin{array}{l}\text { - Lack of motivation and } \\
\text { commitment } \\
\text { - } \quad \text { Failure to realize seriousness } \\
\text { of problem }\end{array}$ \\
\hline $\begin{array}{l}\text { - Government policies for tobaccol } \\
\text { food }\end{array}$ & - Lack of continuity of care & - Older age \\
\hline - Lack of "heart-friendly" infrastructure & $\begin{array}{l}\text { - Fixed clinician perceptions } \\
\text { - Over-burdened with number } \\
\text { of patients }\end{array}$ & $\begin{array}{l}\text { - Female gender } \\
\text { - Low SES }\end{array}$ \\
\hline $\begin{array}{l}\text { - Resource constraints and cost of } \\
\text { equipment and drugs, especially for } \\
\text { noncommunicable diseases }\end{array}$ & $\begin{array}{l}\text { - Lack of understanding of patient } \\
\text { needs } \\
\text { - Costs }\end{array}$ & $\begin{array}{l}\text { - Social isolation, esp. in the } \\
\text { elderly } \\
\text { - Finance-related factors and } \\
\text { costs }\end{array}$ \\
\hline - Lack of advocacy/lobbying & $\begin{array}{l}\text { - Neglecting to involve patients } \\
\text { in choices }\end{array}$ & $\begin{array}{l}\text { - Significant co-morbid } \\
\text { conditions }\end{array}$ \\
\hline $\begin{array}{l}\text { - Poor access and availability of medical } \\
\text { manpower and medicines }\end{array}$ & - Prescribing complex regimens & $\begin{array}{l}\text { - Failure to sustain lifestyle } \\
\text { changes }\end{array}$ \\
\hline $\begin{array}{l}\text { - Media apathy and conflicting } \\
\text { messages }\end{array}$ & - Low clinician referrals & - Lack of quality information \\
\hline $\begin{array}{l}\text { - No insurance cover for COPD } \\
\text { management }\end{array}$ & $\begin{array}{l}\text { - Failure to explain benefits and side } \\
\text { effects }\end{array}$ & - No insurance cover \\
\hline $\begin{array}{l}\text { - Use of nonstandardized formulary } \\
\text { and frequent changes }\end{array}$ & - Lack of focus on lifestyle changes & $\begin{array}{l}\text { - Distance and geographic } \\
\text { factors }\end{array}$ \\
\hline $\begin{array}{l}\text { - Undergraduate medical education } \\
\text { not focused on noncommunicable } \\
\text { diseases }\end{array}$ & - Overtreatment & $\begin{array}{l}\text { - Confusing messages from } \\
\text { multiple stake-holders }\end{array}$ \\
\hline $\begin{array}{l}\text { - Health care system overburdened } \\
\text { with communicable diseases }\end{array}$ & & \\
\hline
\end{tabular}

Abbreviation: SES, socioeconomic status.

information systems are crucial for monitoring the performance of secondary prevention programs. More urgently Indian physicians in primary and secondary care need to increase the use of widely available secondary preventive measures recommended by guidelines. The mandatory use of aspirin, statins, beta-blockers, and ACE inhibitors in all patients are necessary to reduce the increasing mortality from chronic CHD in India.

\section{Acknowledgments}

This work is supported by a grant from South Asian Society of Atherosclerosis and Thrombosis, Bangalore, India. The authors report no conflicts of interest in this work.

\section{References}

1. Balady GJ, Williams MA, Ades PA, et al. Core components of cardiac rehabilitation/ secondary prevention programs: 2007 update. Circulation. 2007;115:2675-2682.

2. Fox K. Stable angina pectoris. In: Compendium of Abridged ESC Guidelines. Nice, France: European Society of Cardiology; 2008. p. 77-89.
3. National Institute of Clinical Excellence. CG48. MI: Secondary prevention: understanding NICE guidelines. Available at: http://www. nice.org.uk/nicemedia/pdf/CG48PublicInfo.pdf.

4. World Health Organisation. Wellcome Trust Meeting Report. Secondary prevention of noncommunicable diseases in low and middle income countries through community-based and health service interventions. WHO Document No. WHO/EDM/2000. Geneva, Switzerland: World Health Organization; 2002.

5. Yusuf S. Two decades of progress in preventing cardiovascular disease. Lancet. 2002;360:2-3.

6. Beaglehole R, Epping-Jordan A, Patel V, et al. Improving the prevention and management of chronic disease in low-income and middle-income countries: a priority for primary health care. Lancet. 2008;372: 940-949.

7. DeWilde S, Carey IM, Richards N, Whincup PH, Cook DG. Trends in secondary prevention of ischemic heart disease in the UK 1994-2005: use of individual and combination treatment. Heart. 2008;94:83-88.

8. Newby LK, LaPointe NMA, Chen AY, et al. Long term adherence to evidence based secondary prevention therapies in coronary artery disease. Circulation. 2006;113:203-212.

9. EUROASPIRE Study Group. EUROASPIRE: A European Society of Cardiology survey of secondary prevention of coronary heart disease, principal results. Eur Heart J. 1997;18:1569-1582.

10. Wood DA; for the EUROASPIRE Group. Clinical realities of coronary prevention: comparison of EUROASPIRE I and II in nine countries. Lancet. 2001;357:995-1001. 
11. Kotseva K, Wood D, De Backer G, et al; for EUROASPIRE Study Group. Cardiovascular prevention guidelines in daily practice: a comparison of EUROASPIRE I, II, and III surveys in eight European countries. Lancet. 2009;373:929-940.

12. Rogers W. Temporal trends in the treatment of over 1.5 million patients with myocardial infarction in the US from 1990 through 1999 The National Registry of Myocardial Infarction 1, 2 and 3. J Am Coll Cardiol. 2000;36:2056-2063.

13. Mendis S, Abegunde D, Yusuf S, et al. WHO study in prevention and recurrence of myocardial infarction and stroke (WHO PREMISE). Bull WHO. 2005;83:820-828.

14. Karthikeyan G, Xavier D, Prabhakaran D, Pais P. Perspectives on the management of coronary artery disease in India. Heart. 2007;93: 1334-1338.

15. Chaturvedi V, Bhargava B. Healthcare delivery for coronary heart disease in India: Where are we headed? Am Heart Hosp J. 2007;5:32-37.

16. Gupta R. Secondary prevention of coronary artery disease in urban Indian primary care. Int J Cardiol. 2009;135:184-186.

17. Xavier D, Pais P, Devereaux PJ, et al. Treatment and outcomes of acute coronary syndromes in India (CREATE): a prospective registry analysis of registry data. Lancet. 2008;371:1435-1442.

18. Chronic Care Foundation of India. Non-communicable Chronic Diseases in India: A study of the gaps, quality and cost of care. New Delhi, India: Chronic Care Foundation of India; 2009. p. 43-105.

19. Department of Health. Updated Version of the QOF Guidance and Evidence Base. London, UK: Department of Health; 2004.

20. Hunink MG, Goldman L, Tosteson AN, et al. The recent decline in mortality from coronary heart disease, 1980-1990. Th effect of secular trends in risk factors and treatment. JAMA. 1997;277:535-542.
21. World Health Organization. Prevention of Cardiovascular Disease. Guidelines for risk assessment and management of cardiovascular risk. Geneva, Switzerland: World Health Organization; 2007.

22. The Heart Outcomes Prevention Evaluation Study Investigators. Effects of an angiotensin-converting-enzyme inhibitor, ramipril, on cardiovascular events in high-risk patients. N Engl J Med. 2000;342: $145-153$.

23. Gupta R. Ramipril: the better angiotensin converting enzyme inhibitor? Indian Heart J. 2008;60:188-191.

24. Gibson CM. NRMI and current treatment patterns for ST-elevation myocardial infarction. Am Heart J. 2004;148:29-33.

25. Fox KA, Goodman SG, Klein W, et al. Management of acute coronary syndromes. Variations in practice and outcome. Findings from the Global Registry of Acute Coronary Events (GRACE). Eur Heart $J$. 2002;23:1177-1189.

26. Gabbay LJ, Le May G. Evidence-based medicine: do we use guidelines or mindlines? BMJ. 2004;329:1013.

27. Aiyar S. Reforms pay, apathy drags. Sixth state of the states report. India Today. 2008;33(38):34-72.

28. Mandelzweig L, Battler A, Boyko V, et al. The second Euro Heart Survey on acute coronary syndromes: characteristics, treatment and outcome of patients with ACS in Europe and the Mediterranean basin in 2004. Eur Heart J. 2006;27:2285-2293.

29. Reddy KS, Shah B, Varghese C, Ramadoss A. Responding to the threat of chronic diseases in India. Lancet. 2005;336:1744-1749.

30. Gupta R, Prakash H, Gupta RR. Economic issues in coronary heart disease prevention in India. J Human Hypertens. 2005;19:655-657.

31. Gupta R, Joshi PP, Mohan V, Reddy KS, Yusuf S. Epidemiology and causation of coronary heart disease in India. Heart. 2008;94:16-26.
Vascular Health and Risk Management

\section{Publish your work in this journal}

Vascular Health and Risk Management is an international, peerreviewed journal of therapeutics and risk management, focusing on concise rapid reporting of clinical studies on the processes involved in the maintenance of vascular health; the monitoring, prevention and treatment of vascular disease and its sequelae; and the involvement of

\section{Dovepress}

metabolic disorders, particularly diabetes. This journal is indexed on PubMed Central and MedLine. The manuscript management system is completely online and includes a very quick and fair peer-review system, which is all easy to use. Visit http://www.dovepress.com/ testimonials.php to read real quotes from published authors. 